\title{
An Exploration of Historical Transitions with Simple Analogies and Empirical Event Rates
}

David J. LePoire

Environmental Science Division, Argonne National Laboratory

\begin{abstract}
Various qualitative models have been suggested for major historical social and technological transitions. Many of these transitions still have puzzling aspects such as the early transition from hunter-gatherer to agriculturallybased society which required dramatically increased effort. Another puzzle is the emergence of the scientific and industrial revolution in Europe despite many previous similar discoveries in other regions. Explorations of simple models with aggregate, dynamic, and nonlinear processes might lead to insights of the unique aspects of each transition. Topics include the transitions between hunter-gatherers, agricultural societies, early civilizations, market development, capitalism, industrialization, and sustainable societies with factors of land-pressures, economies of scale, suppressed growth, and chain reactions.

Many types of models could be applied to these transitions. First, basic characteristics, such as width and midpoint of the transitions, are determined by analyzing historical events contributing to the transition. However, this does give much insight into the dynamics or parameters of the transition. For more understanding, each of six transitions is explored with a simple phenomenological model. These simplified models do not attempt to quantitatively address the details of the actual historical mechanisms Instead analogies to more natural systems are invoked to gain insights.
\end{abstract}

Correspondence | David J. LePoire, dlepoire@anl.gov

Citation | LePoire, D. (2019) An Exploration of Historical Transitions with Simple Analogies and Empirical Event Rates. Journal of Big History, III(2);1 - 16.

DOI | http://dx.doi.org/10.22339/jbh.v3i2.3210

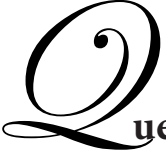

In Big History there are many transitions as complexity seems to grow in natural ecosystems and social historical development [Christian 2014, Volk 2017, LePoire 2015]. The focus of this paper are the historical transitions, which are amenable to analysis and historical study. While many consequences of the transitions have been well described, there are still many questions concerning why the transitions happened at all. For example, why did early farmers leave a seemingly easier lifestyle of the huntergatherer? Why did large seemingly parasitic cities evolve which were dependent on the agriculture around them? Why did the scientific revolution and industrial revolution predominantly first occur in Western Europe even though many of the inventions had been imported from elsewhere? And a current question: Can a civilization so dependent on unsustainable fossil energy consumption find a path to productive sustainability?

In natural ecosystem transitions, often external environmental changes prompt evolution. These changes have included geological changes from drifting continents which created and destroyed seas, and the warming of the sun from its early beginning about 5 billion years ago to the present as it's elemental composition changes. But other changes have been caused by evolution itself, e.g., the arms race of jaws in the Devonian era, and the development of oxygen generation which essentially were poisons to early life until a mechanism was found to control the oxidation process [Fewster 2016]. 
In human evolution, it seems like the changes are mostly like the latter causes, internally generated [Ponting 2007]. One period solves a problem of the previous, then grows and prospers until some limit is reached, causing new problems. Searches then begin for alternative ways of resolving these new problems including new technologies and ways of organizing. Some of these problems manifest themselves as limitations of human population under a given lifestyle and the control of energy and its corresponding pollution. When old solutions no longer work, then reform, reorganization, and new understanding are explored [Tainter 1996, Gunderson 2002]. For example, many energy sources can be very dangerous without proper control- early humans figured out how to control natural fires which could have easily destroyed their environment; agricultural villages enabled greater food (energy) production but generated larger environmental issues in human waste disposal and diseases; and current energy sources generate large amounts of pollution such as $\mathrm{CO}_{2}$ and nuclear waste.

\section{Major Historical Transitions}

Major historical transitions include the agricultural revolution from hunter gatherer to an agricultural lifestyle, the industrial revolution using external energy sources to power large-scale manufacturing, and the current transition to a more energy sustainable lifestyle independent of fossil fuels [Fewster 2016]. However there are some intermediate periods where large changes took place. After settling down into farming villages, a major change involved the development of larger cities with non-agricultural specialties such as management, government, religion, and law. The ancient and classical civilizations start (around 3000 BCE) with the first historical ancient civilizations (Egypt, Mesopotamia, China, and the Indus Valley) and ends with the collapse of the Rome Empire (around $476 \mathrm{AD}$ ), the largest city in the ancient world. (Similarly, the Chinese Han Dynasty lasted over 400 years from $206 \mathrm{BCE}-220 \mathrm{AD}$ ).

However, the industrial revolution did not follow immediately, but instead took over a thousand

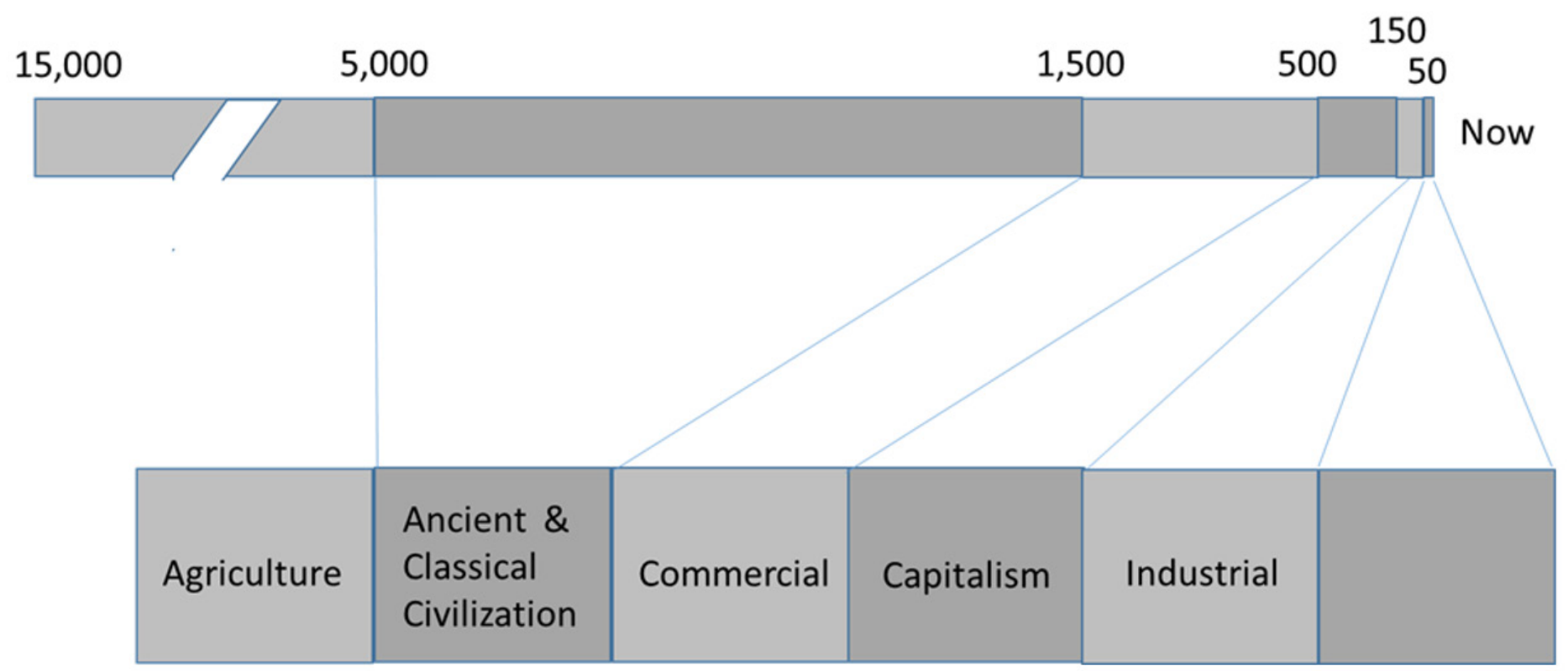

Figure 1. Timeline of historical transitions displayed on a linear time scale (top) and logarithmic scale (bottom). Since there is a factor of 3 reduction in the duration of the phases, each phase has the same width on the logarithmic scale. 
years as the economic foundations for the industrial revolution were developed. Competing political regions developed with the incorporation of growing labor, machinery (technology), and natural energy sources (e.g. wind, water, and wood). A labor market was facilitated by the scarcity of workers after the devastation of the Black Death in the mid 14th century. Trading ships required large investments facilitated by financial tools such as loans, stocks, and insurance. As companies became more efficient, trade in luxury items were later supplemented by bulk trading of wood, fish, and salt. These trading companies could sustainably continue to grow through reinvesting their profits into developing infrastructure such as ports and ships.

There seems to be about 6 phases after the hunter gatherers: early agricultural, early civilization, market development, capitalism, industrial, and sustainability (Figure 1). The six transitions between these phases occurred at about 15000, 5000, 1500, 500, 150, and 50 years ago, i.e., subsequent phases started happening at a quicker pace with a shorter duration. There is about a factor of 3 reduction in the durations between consecutive phases. This factor of 3 is also an approximation for changes in accelerating periods for both natural biological evolution and cultural human evolution as well as this human historical revolution heavily influenced by technology [LePoire 2015] .

\section{Potential modeling approaches}

The modeling of these transitions might occur at many levels of abstraction to gain multiple perspectives [Costanza 1993, Turchin 2003]. For example, modeling methods can be characterized by attributes such as realism, precision, and generality. High-realism models capture as many of the underlying mechanisms at their fundamental levels. High precision models might disregard fundamental understanding and instead be based on empirically derived coefficients. General models may be based on an intermediate conceptual model, highlighting qualitative mechanisms for further strategies but weak in actual numerical predictions and detailed mechanisms.

This study first uses empirical analysis of the transitions by focusing on the rate of important events in the transition. Then an analogy to a physical model is suggested that captures some of the qualitative features of each transition. This study does not attempt to quantitatively address the actual historical mechanisms. Other modeling methods, such as system dynamics models and agent models, might be later used to capture the detailed, disaggregated, and integrated dynamics among the phases.

Various qualitative, narrative explanations have been suggested for other phases of historical transitions. Many of these transitions still have puzzling aspects such as the early transitions from hunter-gatherer to agricultural based society in which the average work day went from a few hours to at least triple that value [Diamond 2005]. Another puzzle that has collected much attention is the explanation of the emergence of the scientific and industrial revolution first in Europe despite many individual similar discoveries previously in other regions [Goldstone 2009].

In a broader context, recent analysis of important events in Big History has shown a logistic trend [Modis, 2002, Panov 2011]. It was suggested that the overall logistic trend is composite, formed by nested logistic growth in discrete learning phases [LePoire 2015]. Discussion has also included comparing this process to evolution of a complex adaptive system with the intensity of energy extraction as a driving parameter [Chaisson 2004, Fox 1988, Marchetti 1980, Jantsch 1980]. The transitions between huntergatherers, agricultural societies, early civilizations, market development, capitalism, industrialization, and sustainable societies are explored with physical analogies to demonstrate the unique aspects of each transition. Topics include land-pressures, economies 


\section{Empirical}

Agricultural Transition
\begin{tabular}{|l|r|r|r|}
\hline Event & Transiton & Time Between \\
\hline Sedentary Hunters & -15000 & 4000 \\
\hline Wild Cereal Tools & -11000 & 2000 \\
\hline Vilages & -9000 & 500 \\
\hline Plant Domectication & -8500 & 500 \\
\hline Animal Domestication & -8000 & 1000 \\
\hline Pottery & -7000 & 1500 \\
\hline Chiefdom & -5500 & 1500 & \\
\hline Metal Tools & -4000 & & \\
\hline
\end{tabular}
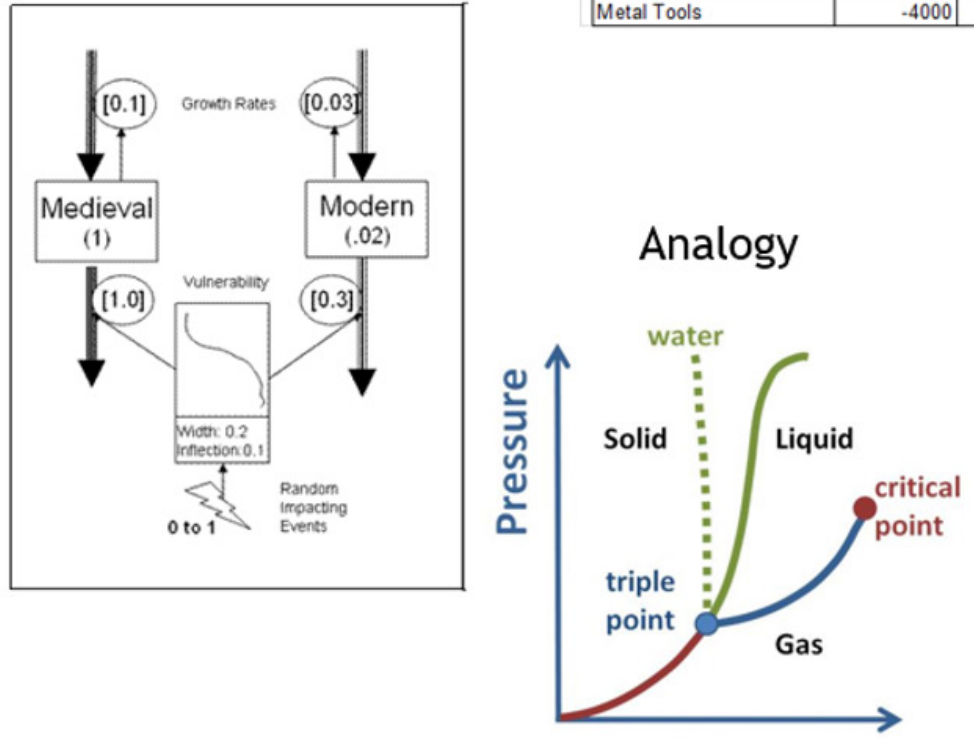

\section{Complex Detailed Model}

Temperature

Figure 2. Various types of models that could be used to understand historical transitions include complex detailed models (right) and system dynamics models (left) that capture key processes in the transition. In this paper, the focus is on empirical rate of events (top) during the transition to determine a midpoint and duration of the transition. Then an analogy (bottom) to a physical model is suggested to help understand the qualitative aspects of the transition.

of scale, suppressed growth, chain reactions, and use of limited energy resources.

\section{Transition to Agriculture}

What caused the transition from a relatively leisurely hunter-gatherer lifestyle to the more work-intensive agricultural lifestyle? It might not be exactly clear, but we do know that all hunter-gatherer societies did not take the path to agriculture even when it was known as an option. For example, some northwestern Native American tribes continued a hunter gatherer lifestyle based on the quite abundant salmon, although due to the resources, they could remain in villages year round.
Perhaps, as long as good conditions continued, the hunter-gatherer lifestyle was adequate. As the population density of hunter-gathers slowly increased, competition (pressure) increased for land. With the greater stress on the natural resources, environmental conditions, such as drought, might reduce the land's productivity. Supplemental intermediate strategies such as slash-and-burn and swidden agricultural were developed. Agricultural land can support many more people than a hunter-gatherer society although it requires more work such as clearing, plowing, planting, nurturing, harvesting, selecting, and storing. The agricultural process also tended to encourage a 
more stationary existence since more investment was required to prepare the land and securely store food and tools.

A hunter-gatherer society could maintain small population growth through techniques such as delayed weaning. In agricultural communities, however, larger families were desired since some jobs were menial and could be performed by younger children. The pressure from these larger agricultural families further increased the competition for land in a positive feedback loop towards coalescence into agricultural communities. This process is similar to a phase transition from a gas (hunter-gatherers) to liquid (farmers) under increased pressure (Figure 3). This dynamic forms the basis of this logistic transition model to agriculture.

The model has two distinct populations of huntergatherers and farmers. Both compete for the land resources, although the farmers require a much smaller (e.g., a tenth) land area per person to support their lifestyle. If the population density is low, most people would continue the easier work of the hunter-gatherer lifestyle. This population grows slowly over thousands of years. Eventually, larger populations require most of the local area (which may be diminished due to land loss due to environmental or natural causes). The effort to live on such a densely populated area increases due to competition for the limited resources (e.g, wildlife). A few hunter-gatherers might try new approaches to secure food. As agriculture knowledge grows, eventually some people will settle down as farmers. However, this agricultural lifestyle is able to feed more people and use the children at an earlier age, increasing the population growth rate. This tends to propagate the lifestyle by increasing the competition for land (land pressure) which causes more hunter-gatherers to switch to farmers. Therefore, the transition continues towards agriculture with the important factors driving the transition being the relative land pressure and growth rates.

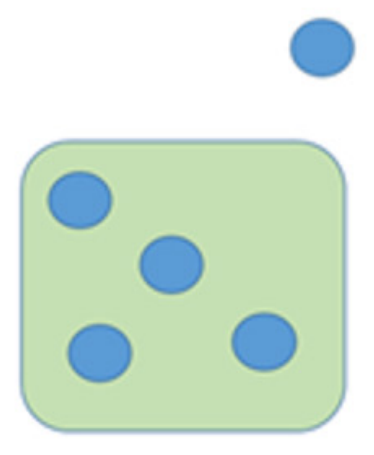

Hunter-Gatherers with a relative leisurely existence on land that easily support them.

\section{Amount of land required to sustain a hunter-gatherer}

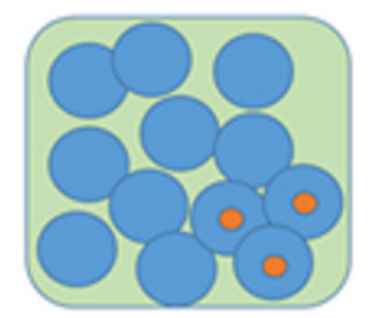

Through population growth (more circles) or changing environmental conditions (larger circles), the pressure on the land increased to where the land could no longer support the lifestyle.

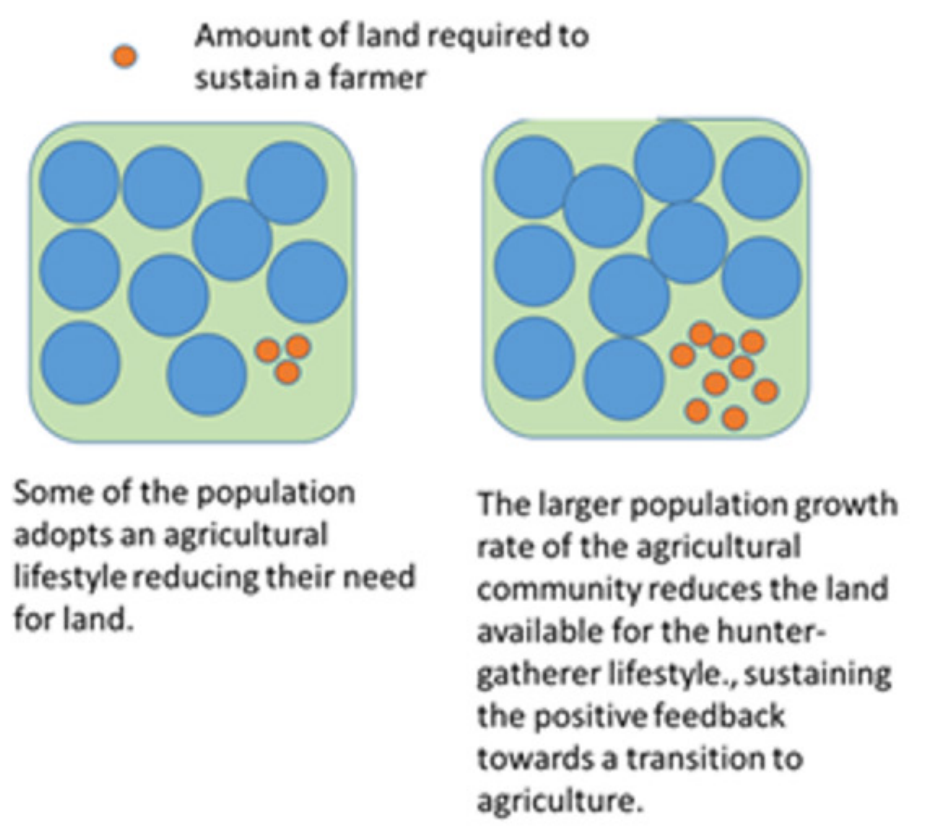

Some of the population adopts an agricultural lifestyle reducing their need for land.

Figure 3. Analogy of transition to an agricultural lifestyle based on land pressure leading to condensation into smaller but more intensive units. 
Evidence of intermediate events can be used to estimate the duration and midpoint of the transition. A list of important events in during various development phases was constructed and analyzed corresponding to logistic (or learning) pattern (Figure 4). For example, Diamond [2005] discusses some important events in the transition from hunter-gatherer to agriculture. If each event is treated as being equally important, then this rate of events can be used to form a logistic curve. What one expects from this logistic pattern is a slow rate of events (discoveries) early in the transition process, followed by a quicker discovery rate, with the quickest rate at the inflection point halfway through the transition. Then a another slower phases of discoveries follows, near the end of the transition. The beginning of the transition was about 15,000 years ago with the exploration of sedentary hunters. The inflection point was about 9,000 years ago (7,000 BCE), with forms of plant domestication. The last major event putting the transition over $90 \%$ was the introduction of metal tools at about 5,000 years ago $(3,000 \mathrm{BCE})$. The duration of the transition from $10 \%$ to $90 \%$ was about 9,000 years.

\section{Transition to Civilization}

The development of cities around agricultural communities happened independently at a few location at various times in history, e.g., Mesopotamia, Nile, Indus, China, and Central America. The urban inhabitants exchanged protection, administration, and specialized crafts for surplus food from the rural communities. Administration included overseeing large public projects such as irrigation and food storage. The urban elite's role was to

Agricultural Transition
\begin{tabular}{|l|r|r|}
\hline Event & Transiton & Time Between \\
\hline Sedentary Hunters & -15000 & 4000 \\
\hline Wild Cereal Tools & -11000 & 2000 \\
\hline Villages & -9000 & 500 \\
\hline Plant Domectication & -8500 & 500 \\
\hline Animal Domestication & -8000 & 1000 \\
\hline Pottery & -7000 & 1500 \\
\hline Chiefdom & -5500 & 1500 \\
\hline Metal Tools & -4000 & \\
\hline
\end{tabular}

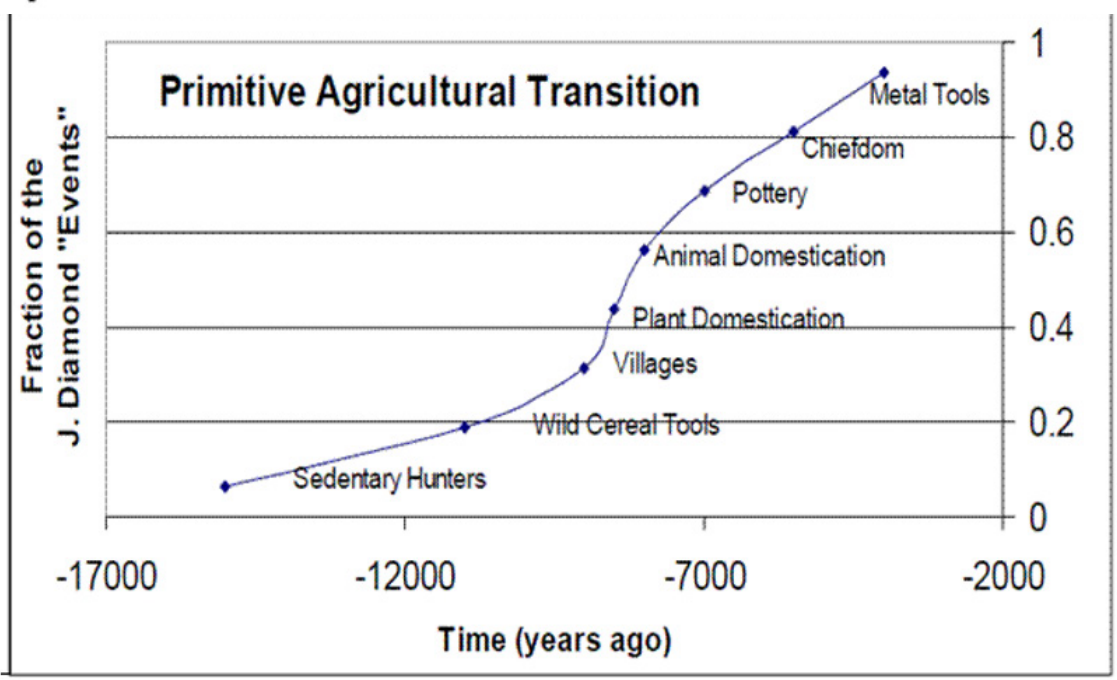

Hunter-Gatherer to Agriculture Transition Model

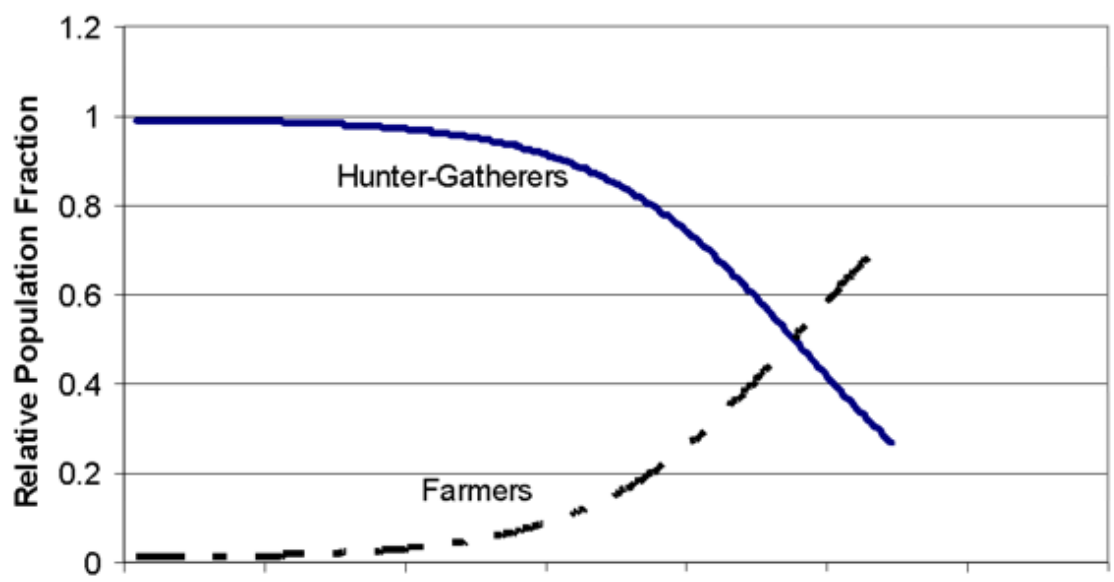

Figure 4. Logistic Trend of major events in the transition to primitive agricultural societies. 
manage such risks as invasion and famine to ensure continued growth. This risk management was more important in areas where the population density was higher and natural disasters like floods and famine were more frequent. Decisions to centralize or decentralize organizations remains a key current issue and is dependent on complex considerations of the return on scale of various processes. The exploration and learning in this transition during the ancient and classical civilizations led to one of the largest and centralized empires based around a large city- the Roman Empire where about 20\% of the population was either an urban dweller or in the military [Ponting 2007]. However, its highly centralized nature led to dependence on dynamic growth for capturing new area and sources of labor to support the system.

The transition from agriculture villages to hierarchical civilizations is modeled with increasing economies of scale. That is as the city becomes larger the relative cost to the dwellers becomes less expensive. The agriculture villages were more susceptible to natural risks such as drought and flooding, which reduce their population growth. A hierarchical civilization allowed a management of food storage and mitigation of natural impacts with such tools as irrigation. The benefit of this investment in the administration and resource collection would be the capability to be more resilient when natural disasters occurred. Later as civilizations became more prevalent, war and diseases would also be added to the natural disasters. The impact of natural disasters would be larger near the more marginal lands. While at first, the natural river systems of Egypt and the fertile crescent provided suitable conditions, later civilizations further spread with the introduction of new technologies based on better materials such as bronze and iron.

This model, based on economies of scale of specialized management of risks, is portrayed in figure 5. The transition to new levels of civilization proceeds when the mitigation of risks allows for larger average growth. Positive feedbacks arise from the relative military power of the more centralized state.

The sequence of dynastic (or national) durations from Mesopotamia and Egypt is shown in Table 2. The process starts at about 3,000 BCE with early

\section{Traditional Agriculture}

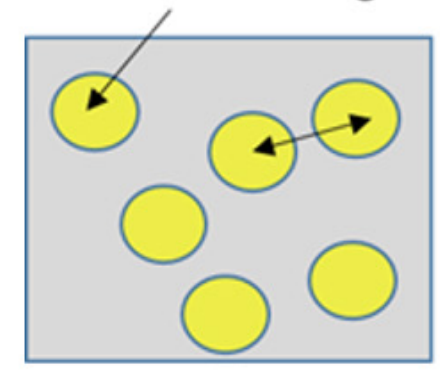

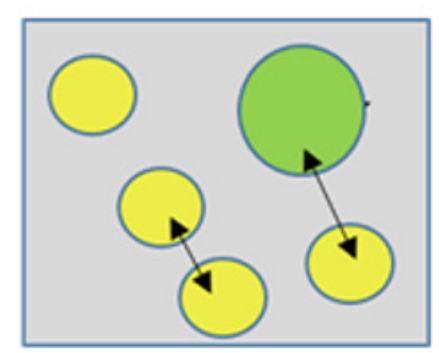

Hierarchical Civilization

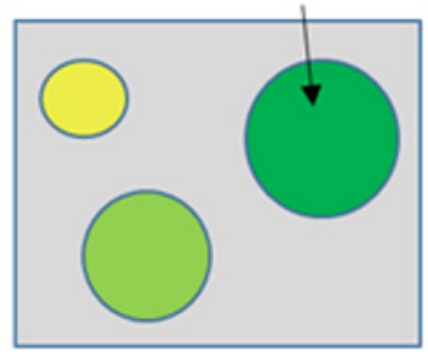

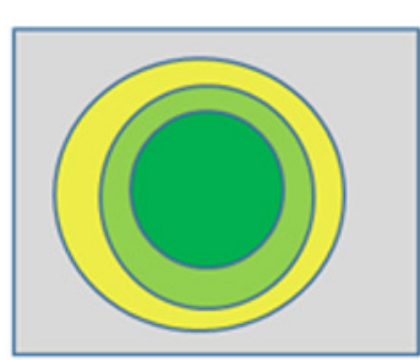

\section{Control (Time)}

Figure 5. Consolidation model of civilization growth. As agricultural density grows, risk increases with the use of marginal lands and conflicts. A way to mitigate these risks is by forming a hierarchy to organize and distribute. The overhead needed for a hierarchy is smaller (on per person basis) with larger sizes (forming an economy of scale). If the technology changes to enable wider control then more consolidation may take place. 
civilizations of Ur and Egypt. Empires rise and fall through learning processes such as incorporating new technologies, government organization, coordination of land and water rights, and developing military defenses. The dynastic duration tends to shorten in time before the midpoint inflection. This inflection, near $600 \mathrm{BCE}$, is near the collapse of many Bronze Age civilizations which occurred during the Greek Dark Ages. This inflection point is also near the middle of the Axial Age as Jaspers [1953] described it as "an interregnum between two ages of great empire, a pause for liberty, a deep breath bringing the most lucid consciousness." After this inflection point, ideas and technologies, such as iron working, were developed, and the duration of the major empires began to lengthen again leading to the Roman Empire and its direct related civilization the Byzantine Empire ending at about 1,000 AD. Both these empires were still built around one large city, Rome and Byzantium (Constantinople). However, while technology led to many infrastructure developments (such as water systems, ports, buildings and roads), the major energy input was based on agriculture with dependence on slave-based labor [Ponting 2007].

\section{Transition to Commercial Markets}

The Roman Empire generated many wonders which would not be duplicated for centuries after its collapse, generally taken to be around 476 . However, a new form of civilization was being formed, by the groups exposed to the Roman technology but with more decentralized government and without the slave-based economy of the Romans. The internal fighting occurred over many years as new growth and arrival of new tribes led to their invasion into previously settled land such as the Huns, Germanic tribes, and Vikings. A spell of warmer weather, Medieval Warm Period (950-1250), which allowed higher agricultural yields and therefore higher population, was partially responsible for these expansions.

\section{Ancient/Classic Civilization}

\begin{tabular}{|l|r|r|}
\hline Event & Transiton & Time Between \\
\hline Sumer/Egyptian Old & -3000 & 787.5 \\
\hline Bablyon / Egyptian Mid & -2212.5 & 580 \\
\hline Hittite / Egyptian New & -1632.5 & 432.5 \\
\hline Kassite & -1200 & 300 \\
\hline Assyrian & -900 & 292 \\
\hline Chaldean & -608 & 46 \\
\hline Persian & -562 & 228 \\
\hline Helenistic & -334 & 201 \\
\hline Rome & -133 & 621 \\
\hline Byzantine & 488 & 965 \\
\hline (End of Byzantine) & 1453 & \\
\hline
\end{tabular}

Early Civilization Logistic Fit

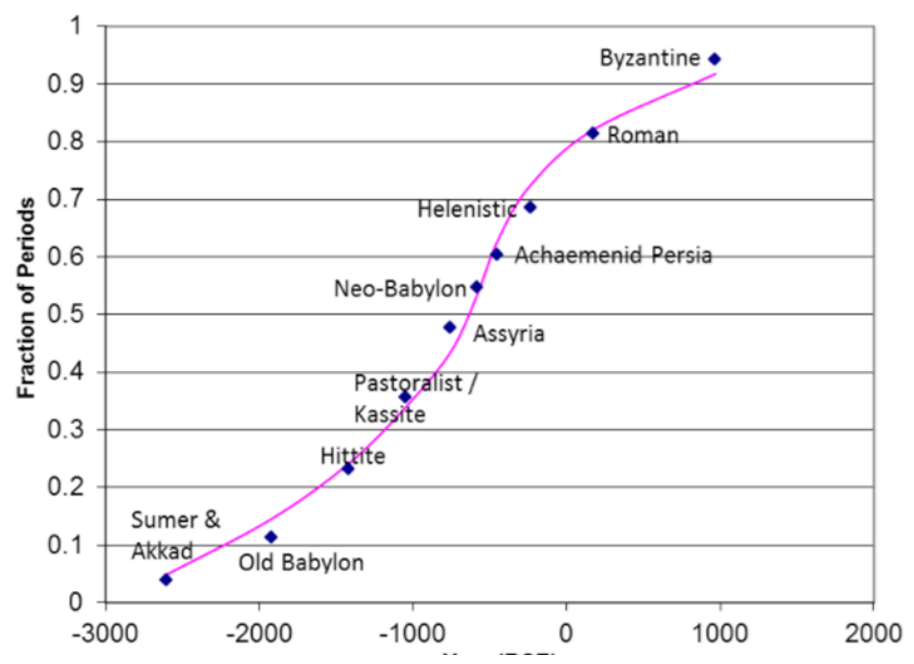

Figure 6. The transition through early civilization (ancient and classical) based on the duration of leading states.

An important set of events led to the establishment of wider trading routes. These events included the expansion of Islam into Spain with the secured knowledge of previous civilizations; the crusades inspired to minimize internal European fighting was supported by growing trade in Byzantium and Italian city-states; the development and diffusion of technology which utilized natural resources such 

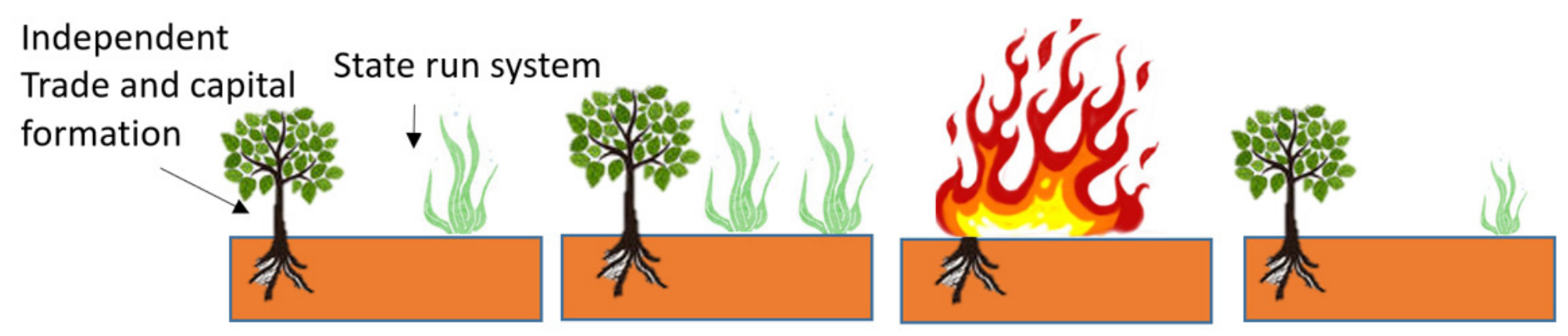

\section{Time}

Figure 7. Prairie model of commercial market growth. While the growth rate of weeds (state intervention in the economy) is faster than prairie plants (market growth), periodic fires (disagreements between states) lead to the prairie plants' resilience with deeper roots.

as wood, water, and animals more efficiently, as exemplified by the Cistercians Monks [Gimpel 1976]; and the establishment of a northern European trade network independent of any one state, the Hanseatic League, which began to trade bulk goods such as fish, wood, and wheat. The slimmer profit margins from these bulk goods required more efficient ships and commercial mechanisms.

To construct a timeline, the events in the commercial revolution in Europe are identified [Lopez 1976, Ferguson 2008]. As described above, these events took place between the fall of Rome and the establishment of sustainable capitalism in northern Europe in the 17th century. The beginnings started with the Italian city-states such as Venice which had maintained relationships until 742 with the Byzantine Empire after the fall of Rome. Early market fairs such as the Saint Denis Fair near Paris started in the 7th century as a side-product of religious pilgrimage. In the Viking trading routes formed beginning in the 9th century across Europe including from the Baltic to the Black Sea. This continued in the 12th and 13th centuries with greater trade in Europe from lessons learned from the crusades and led to Champagne fairs. In the north the Hanseatic trading League developed in the 13th and 14th centuries. After the fall of Constantinople in 1453 , new routes were explored to bypass the Eastern Mediterranean. This motivated exploration by the Portuguese and later by the Spanish, Dutch, English, and French. The luxury goods trade was transitioned to bulk goods in the northwestern Europe leading to economies of scale for bulk goods and introduce new business organization to share risks (see next section).

The characteristics of the model should include the hindrance of European unification (although the Holy Roman Empire and Habsburgs had attempted to form large empires), allowing more market competition, experimentation and growth of innovations such as various markets and financial tools in loose commercial networks which included the Italian City states and the Hanseatic League. This suggests a process similar to what happens in prairie ecosystems. Prairies consist of both slow growing grasses with deep roots and fast growing plants (weeds) with shallow roots. The prairie grasses can establish themselves only if natural occurring fires occur which destroy the faster growing plants but leaving the resilient deep grass roots untouched. In a similar way, markets systems (prairie grass) in Europe might have been able to grow, e.g., independent investments and banking systems, 
because of the absence of unified states to hinder trade growth through state interventions (weeds).

\section{Transition to Capitalism}

The commercial markets and the trade of bulk items such as lumber and fish (instead of relying on mostly luxury goods), facilitated the introduction of capital formation often in the form of securing trading ships. The components of the system such as stock markets, loans, banking, legal obligations, and insurance were established during the commercial market phase [Ferguson 2008]. However, the independence of the European states meant that each state had its own way of experimenting with markets and relative interference. In 17th century the Dutch gained political independence from Spain leading to the Dutch Golden Age of art, commerce and exploration. The relative smallness of the country allowed for ideas to spread rapidly through the main financial center of Amsterdam. They also participated in the protestant reformation and also the scientific revolution with the likes of Huygens and van Leeuwenhoek.

While the riches began to accumulate in the Netherlands during their Golden Age with the arts and culture, other countries followed but on a larger scale. The English and Dutch had major naval battles to determine primacy in trade and economic development. The English established themselves as leaders after their civil war and instability by inviting the Dutch king to be their own in the Glorious Revolution of 1688. England's population at the time was roughly twice the Dutch population. This pattern seemed to continue that leadership would pass after about a century to a state that was twice as large in population. This included the transition to the full United Kingdom (which included Scotland and Wales) in the 19th century and then to the U.S. There might be one or two possible future transitions [LePoire 2010]. The pattern with the 4 transitions over the 400 years, suggests a midpoint at about 1800 .

The analogy for this growth of capitalismis the growth of an individual fertilized egg cell during development to a multicellular organism. This pattern in the growth of capitalism is complicated by the necessity for a sequence of transitions to larger countries. The larger countries can supply larger markets and more complex infrastructure. This infrastructure includes not only the physical items such as roads and communications
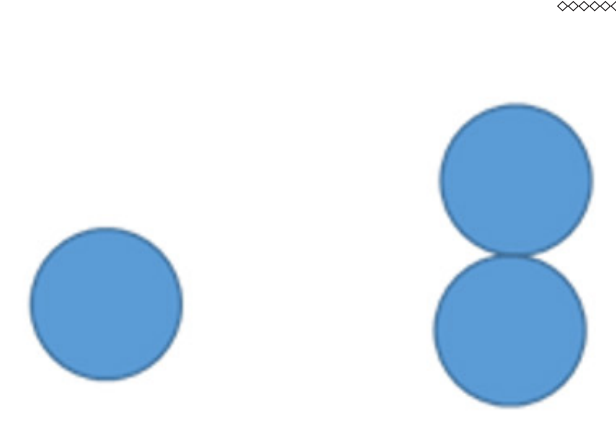

\section{Netherlands England}

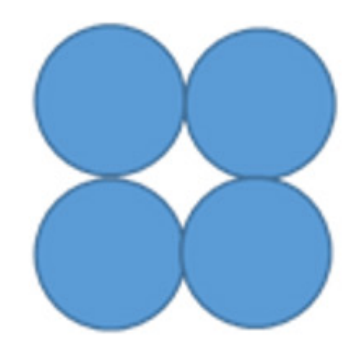

UK

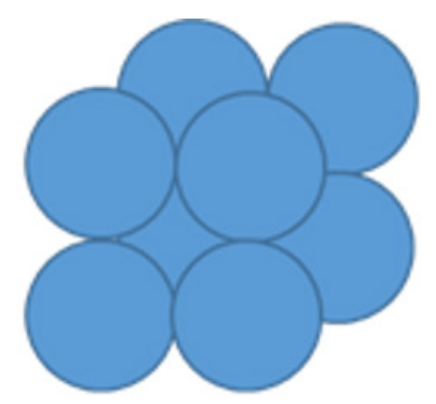

USA

\section{0}

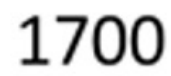

1800

1900

2000

Figure 8. Transition to capitalism as the center of leadership shifts about every century to a location double in size (at the time of transition). 
but also the social organizations such as governments and laws. Both cells and economicleadership transition by splitting on a periodic bases (cells: about a day; capitalist leadership about every 100 years). Another difference is that the biological growth is done without addition of any new material (for up to 16 cells) but in the capitalistic leadership transition, the nations grow between the transitions.

\section{Transition to Industrial}

As population, trade, and demand for goods increased, energy in the form of water, wood, and wind were limited. This was felt early in England as the forests were depleted, however, this led to exploration of the use of coal which required greater transportation and technology to keep the mines dry. The resulting use of iron and steam engines led to a positive feedback loop in which the technologies used to develop coal resources led to increased coal demand. This system first emerged in the Severn River valley in the mid 1700 's. However, many of these technologies had been tried before: blast furnaces were used for iron working in Han China; coke from coal was used for metallurgy in Song China; and Hero of Alexandria constructed a steam powered device and an early windwheel in the 1st century (although not very efficient).

The puzzle why Europe led the scientific and industrial revolution has been discussed quite thoroughly in the past with many explanations [Goldstone 2009, Stark 2005]. Diamond [2005] suggested that geography played an important role in that China had few natural hindrances enabling the establishment of a centralized government whereas Europe had many mountain ranges and a complicated coastline. The Chinese Han dynasty has been likened to the Roman Empire, however, after its collapse, only a few generations passed before the reestablishment of a centralized government which was able to manage the introduction of technologies and innovations. Others have explored this theory more quantitatively in looking at the fractal dimension of the coastlines in enabling trade and reducing the chance of a centralized government [Cosandey 1997].

Why did these earlier inventions not start a similar industrial age? Perhaps combinations of the technologies must occur in a short period under conditions that could sustain growth and continual development. These incentives include the ability of the entrepreneur to profit from capital investments, and the workers the ability to leave the land and work instead in factories. However, if the cultural environment is not able to sustain growth with accompanying complementary innovations, then the momentum is lost.

The industrial revolution had many phases including an early agricultural phase (mid 18th century) with the introduction of mechanization and advanced crop rotation leading to higher productivities. The other phases in Schumpeter's waves of innovation include the textiles and iron (mid 19th century), steam-rail-and steel, electricity-chemicals and internal combustion engine (late 19th century), and petrochemicalelectronics and aviation (mid 20th century) [Ayres 1989]. Another wave in the sequence might be the information age with digital networks and software. The rate of innovation can be seen in the number of innovations throughout the era. Analysis of a different set of data show the peak in innovation per capita in the late 19th century [Heubner 2005]. This can be viewed as the highest qualitative (i.e., change in life-style) acceleration, while the current acceleration is more quantitative with a larger population contributing to innovation.

The analogy of a chain reaction models the positive feedback of introducing new innovations and the loss of momentum as the innovations age. The new innovations might come from outside (diffusion through trade) or from internal discoveries. A couple of positive feedbacks occurred: 1) as more people worked in the industrial sector evaluating 


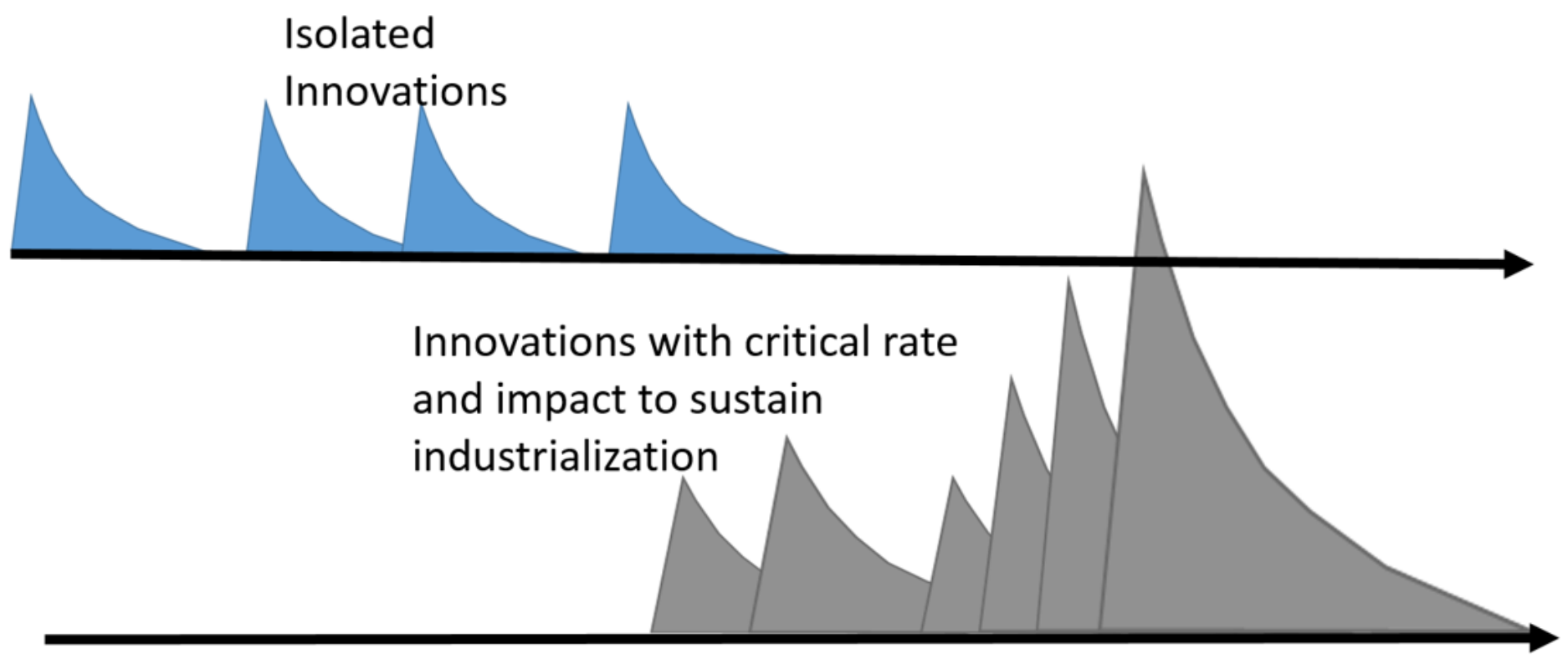

\section{Time}

Figure 9. Critical innovation rate model of transition to industrialization. The top shows a society with early innovations but are isolated and do not influence each other. The bottom case is a society that has innovations quickly introduced but each with a longer duration impact. The innovations create a chain reaction.

and implementing new technologies, workers in traditional setting, e.g., agriculture, were no longer needed because of the labor saving devices such as tractors; and 2) new innovations result in a greater number of potential innovations based on increased combinations. However, if the rate of innovations is too slow, they might be forgotten or taken for granted before the next innovation. This leads to a rather slower linear progression compared to the exponential growth with the positive feedbacks at higher innovation rates. Physical and social technologies such as coal, steel, steam power, democracy, capital markets, and communication were brought together in a system able to sustain the transition through their continuous need for innovation. A key factor is the ability to recognize and monitor the feedback to grow or abandon decisions based on market conditions and financial incentives.

\section{Current Transition}

The current transition is towards a sustainable civilization where energy, population, and technology are balanced. The transition is complicated by the need to solve the current problems without creating overwhelming new ones within the context of rapidly changing technology [Homer-Dixon 2006, Ausubel 1996]. For example, raising education and health of many people, especially women in developing countries, temporarily increases resource use through improved quality of life before the population growth rates stabilize. If the transition progresses too slow, the resources will not be concentrated enough and the solutions will not be found. If the transition goes too fast, the unresolved unintended problems will accumulate.

The "burnout" or sustainability model is known within many communities including ecology. Transitions in predator-prey models sometimes exhibit 
the "J-Curve" where the transition starts going through the characteristic S-Curve but does not stabilize at the higher level but instead collapses to a lower level. This is indicative of fueling the initial growth on some unsustainable resource.

An analogy is made between the transition to a sustainable society to launching a rocket into orbit [LePoire 2018]. A rocket, once launched, needs to reach a critical velocity and height before obtaining a sustainable orbit. Once a stable orbit is attained, there are many further beneficial options such as space observations or facilitating further space exploration. The basis for the analogy is that there are two stationary states for the rocket- the ground and a stable orbit. The ground is analogous to the historical situation of a society based on traditional solar energy for crop growth, warmth, wind, and water. The stable orbit is analogous to an improved situation of an advanced society with more freedom, comforts and fulfillment, which is also stable through technologically capturing a larger fraction of the solar energy (or supplementing it with nuclear fission or fusion).

It is not clear if society's transition to energy sustainability (the metaphorical stable orbit) will be completed successfully. In this analogy, it is not at all clear which plan we should follow towards sustainability since we really do not know the fundamentals that any rocket engineer would know. Such information would include the weight of the rocket, the efficiency of the engines, the amount of fuel, the speed necessary to get into orbit, and the height of the orbit such that the atmosphere is negligible.

A rocket launch can crash from loss of stability, fuel tank explosion, too little acceleration leading to inefficient use of fuel, too much acceleration damaging engines. The rocket might also heat up too much when going through the atmosphere or if the orbit is too low. The rocket might not orient correctly for a stable orbit. Another failure would be for the rocket to enter a stable

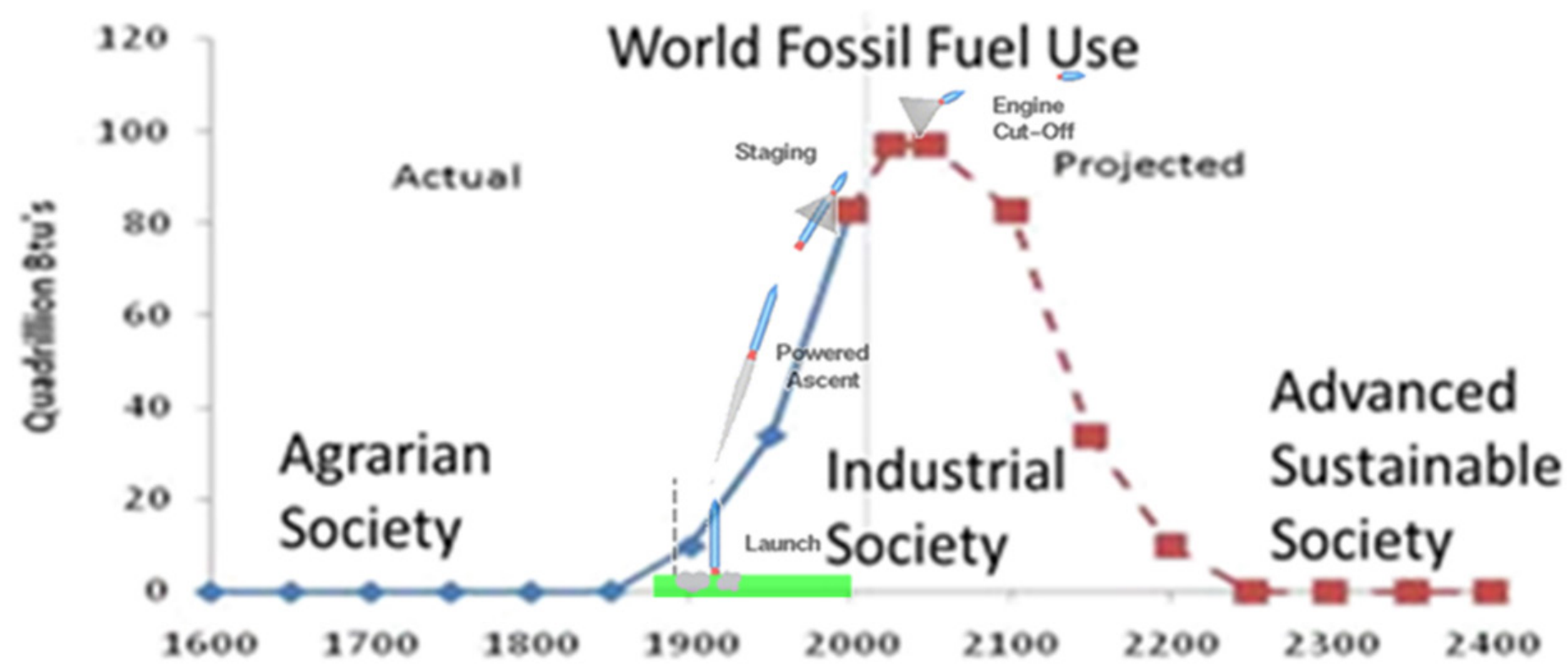

Figure 10. The analogy of a rocket launching into orbit with the launching of civilization into an industrial society based on the use of fossil fuel. Both start at a lower stable state (ground and agrarian society) but use the limit energy resources to reach a stable state at a higher level (orbit and advanced sustainable society). 


\begin{tabular}{|c|c|c|c|c|}
\hline Transition & $\begin{array}{l}\text { Approx. Beginning } \\
\text { Point }\end{array}$ & Analogy & Parameters & Characteristics \\
\hline Agriculture & $\begin{array}{l}13,000 \text { BCE } \\
(15,000 \text { ya) }\end{array}$ & $\begin{array}{l}\text { Phase transition } \\
\text { between gas } \\
\text { and liquid as the } \\
\text { pressure increases. }\end{array}$ & Land pressure & $\begin{array}{l}\text { Not reversible } \\
\text { unless land pressure } \\
\text { is reduced through } \\
\text { technology or } \\
\text { catastrophic } \\
\text { population reduction }\end{array}$ \\
\hline $\begin{array}{l}\text { (Ancient and } \\
\text { Classical) } \\
\text { Civilization }\end{array}$ & $\begin{array}{l}3000 \mathrm{BCE}(5,000 \\
\text { ya) }\end{array}$ & $\begin{array}{l}\text { Centralize / } \\
\text { decentralize } \\
\text { Insurance model } \\
\text { based on return of } \\
\text { scales } \\
\end{array}$ & $\begin{array}{l}\text { Benefits of } \\
\text { centralization }\end{array}$ & $\begin{array}{l}\text { Stochastic and } \\
\text { reversible depending } \\
\text { on random } \\
\text { impacting events }\end{array}$ \\
\hline $\begin{array}{l}\text { Commercial } \\
\text { Market }\end{array}$ & 500 (1500 ya) & $\begin{array}{l}\text { Prairie ecosystem } \\
\text { sustainability } \\
\text { through frequent } \\
\text { fires which do not } \\
\text { burn deep rooted } \\
\text { grasses }\end{array}$ & Fractionation & $\begin{array}{l}\text { Stochastic and } \\
\text { reversible bases on } \\
\text { impacting events } \\
\text { hindering further } \\
\text { centralization }\end{array}$ \\
\hline Capitalism & 1550 (450 ya) & $\begin{array}{l}\text { Early growth of an } \\
\text { organism from one } \\
\text { cell to many. }\end{array}$ & $\begin{array}{l}\text { Division rate, rate of } \\
\text { growth }\end{array}$ & $\begin{array}{l}\text { Needs to start small } \\
\text { and have nearby } \\
\text { areas that can take } \\
\text { the lead when } \\
\text { divisions happen. }\end{array}$ \\
\hline Industrial & 1850 (160 уа) & $\begin{array}{l}\text { Critical innovation } \\
\text { rate model }\end{array}$ & $\begin{array}{l}\text { Rate and duration of } \\
\text { impact of introduced } \\
\text { innovations }\end{array}$ & $\begin{array}{l}\text { Stochastic and } \\
\text { reversible depending } \\
\text { on growth rate due } \\
\text { to innovations and } \\
\text { technologies }\end{array}$ \\
\hline Sustainable & 1960 (60 уа) & $\begin{array}{l}\text { Rocket launching } \\
\text { model- society } \\
\text { consumes fossil fuel } \\
\text { resources in attempt } \\
\text { to reach a new level } \\
\text { of sustainability } \\
\text { (orbit). }\end{array}$ & $\begin{array}{l}\text { Technology } \\
\text { substitution ability, } \\
\text { demographics } \\
\text { transition rates }\end{array}$ & $\begin{array}{l}\text { Irreversible because } \\
\text { the stock of non- } \\
\text { renewable resources } \\
\text { (e.g., oil) can only } \\
\text { support one attempt } \\
\text { at this transition. }\end{array}$ \\
\hline
\end{tabular}

Table 1. Summary of the six transitions and their analogies presented in this paper. 
orbit but lose the capability to support humans, e.g., buildup of carbon dioxide as started on the ill-fated Apollo 13. For each of these there are corresponding analogies in the transition to an advanced sustainable society. For example, the incentives might not be correct to guide us towards stability, the transition might be too slow (burning fossil fuels but making too little progress) or too fast (using technology that eventually is inappropriate or inefficient).

\section{Summary}

A topic of current discussion concerns the rate of technological progress, energy usage, and social change. One contribution to this discussion is historical analysis of important historical transitions. These transitions include development from hunter-gathers, to farmers, to civilizations, to market development, and capitalism. The rate of important events within these transitions indicate potential logistic trends. This trend throughout historical civilizations continues the accelerating rate of biological and human evolution, which seems to be leading to a nearing inflection period (as some have called the singularity). This growth trend might also be viewed as a behavior exhibited by a complex adaptive system. As these systems develop further from equilibrium towards critical states, the systems spontaneously may bifurcate into two potential discrete states. The growth between the bifurcations might exhibit recursive logistic growth. The formation of a larger logistic trend by embedded nested transitions might be interpreted as a form of punctuated equilibrium. It has been suggested that energy usage might be the driving parameter for this generalized evolution.

Acknowledgement: This work was supported by the U.S. Department of Energy under Contract No. DEAC02-06CH11357

\section{References}

Ausubel, J. H., 1996. “Can technology spare the earth?” American Scientist 84(2): 166-178.

Ayres, Robert, 1989. "Technological Transformations and Long Waves” RR-89-1, International Institute for Applied Systems Analysis, Laxenburg, Austria.

Chaisson, E. 2004. “Complexity: An energetics agenda: Energy as the motor of evolution." Complexity 9 (3): 14-21.

Christian, D., C. Stokes Brown, C. Benjamin, 2014. Big History: Between Nothing and Everything. McGraw HIll Education, NY, NY.

Cosandey, D., 1997. Le Secret de l'Occident (The Secret of the West), Arléa, Paris, France

Costanza, R., Wainger, L., Folke, C. and Mäler, K-G., 1993. "Modeling complex ecological economic systems: Toward an evolutionary, dynamic understanding of people and nature." BioScience 43: 545-555.

Diamond, J. M., 2005. Collapse : How societies choose to fail or succeed. New York, Viking.

Ferguson, N, 2008. The Ascent of Money: The Financial History of the World. New York, Penguin.

Fewster, Helen (lead editor) 2016. Big History. DK / Penguin Random House

Fox, R. F. 1988. Energy and the evolution of life. New York, W.H. Freeman.

Gimpel, Jean, 1976. The Medieval Machine: The Industrial Revolution of the Middle Ages, Barnes and Noble.

Goldstone, J.A., 2009. Why Europe?, McGraw Hill, N.Y., N.Y..

Gunderson, L. H., and C.S. Holling, 2002. Panarchy: Understanding Transformations in Human and Natural Systems. Washington D.C., Island Press.

Huebner, Jonathan, 2005. A Possible Declining Trend for Worldwide Innovation, Technological Forecasting and Social Change, 72, 980-986.

Homer-Dixon, T. F., 2006. The upside of down : catastrophe, creativity, and the renewal of civilization. Washington, Island Press.

Jantsch, E. 1980. The Self-Organizing Universe: Scientific and Human Implications of the Emerging Paradigm of Evolution. Oxford, UK: Pergamon. 
Jaspers, Karl, 1953, The Origin and Goal of History, Bullock, London: Routledge.

LePoire, D., 2010. "Long-term Population, Productivity, and Energy Use Trends in the Sequence of Leading Capitalist Nations." Technological Forecasting and Social Change.

LePoire, D.J., 2015. Interpreting Big History as Complex Adaptive System Dynamics with Nested Logistic Transitions in Energy Flow and Organization. Emergence: Complexity \& Organization, March 31.

LePoire, D.J., 2018. Rocketing to Energy Sustainability, Journal of Big History, Vol 2, No. 2, https://doi.org/10.22339/jbh. v2i2.2304.

Lopez, R.S. 1976, The Commercial Revolution of the Middle Ages, 950-1350, Cambridge University Press.

Marchetti, C. 1980. "Society as a Learning System: Discovery, Invention, and Innovation Cycles Revisited." Technological Forecasting and Social Change 18:267-282.

Modis, T., 2002. Forecasting the growth of complexity and change, Technol. Forecast. Soc. Chang. 69, 377-404.

Panov, A. D., 2011. "Post-Singular Evolutions and Post-Singular Civilizations." In Evolution: A Big History Perspective, edited by L. E. Grinin, A. V. Korotayev, and B. H. Rodrigue, 212-231. Volgograd: Uchitel.

Ponting, C. 2007. A New Green History of the World: The Environment and the Collapse of Great Civilizations. New York: Penguin Books.

Stark, R., 2005, The Victory of Reason, Random House.

Tainter, J. A. 1996. "Complexity, Problem Solving, and Sustainable Societies." In Getting Down to Earth, edited by R. Constanza, O., Segura, and J. Martinez-Alier, 61-76. Washington, D.C.: Island Press.

Turchin, P., 2003. Historical dynamics: Why States Rise and Fall. Princeton, Princeton University Press.

Volk, J., 2017. From Quarks to Culture: How We Came to Be, Columbia University Press. 